\title{
Can competitive ability predict structure in experimental plant communities?
}

\author{
Fraser, Lauchlan H..$^{*}$ \& Keddy, Paul A. ${ }^{2}$ \\ ${ }^{1}$ Department of Natural Resource Science, Thompson Rivers University, Kamloops, British Columbia, V2C 5N3, Canada; \\ ${ }^{2}$ Department of Biological Sciences, Southeastern Louisiana University, Hammond, LA 70402, USA; pkeddy@selu.edu; \\ ${ }^{*}$ Corresponding author; Fax +1 2508285450; E-mail lfraser@tru.ca
}

\begin{abstract}
Question: Two questions were posed: 1. Can an independent measure of relative competitive ability be used to predict the abundance of species in mixtures? 2. Is the success of those predictions affected by low fertility (stress simulation) or clipping (disturbance simulation)?

Location: Greenhouse at Carleton University, Ottawa, Canada. Methods: We collected adult plant ramets of 11 species from the field and transplanted one ramet of each species into 56 containers of $60 \mathrm{~L}$. We applied a $4 \times 2$ factorial combination of fertilization (none, full nutrients except $\mathrm{N}$, full nutrients except $\mathrm{P}$, full nutrients) and clipping (no clipping, clipping to $10 \mathrm{~cm}$ above soil) with seven replicates of each treatment. After two growing seasons the above- and below-ground biomass of each species was determined.

Results: Regression analyses uncovered a significant positive relationship between plant biomass (measured in this study) and relative competitive ability (as measured in an independent study) under all experimental conditions. Both the mean slope and mean $R^{2}$ were lowest in treatments with low nutrients and highest in the full nutrient treatment (irrespective of clipping).

Conclusions: Our results show that (1) at high fertility, relative competitive ability can generally predict the abundance of species in experimental plant communities, and (2) the intensity of competition (inferred from the magnitude of the slope or $R^{2}$ ) increased with increasing nutrient supply, particularly nitrogen.
\end{abstract}

Keywords: Clipping; Fertility; Predictive ecology; Resource supply; Species abundance; Wetland.

Nomenclature: Gleason \& Cronquist (1991).

\section{Introduction}

One of the central objectives of ecology is the discovery and refinement of general predictive relationships among plant traits, environmental factors and ecological communities (e.g. Rigler 1982; Keddy 1987; Peters 1992; Shipley 2000). Since competition is one of the main factors that structure plant communities (Weaver \& Clements 1929; Grime 1979; Keddy 2001), it would seem likely that the relative competitive ability of a plant should be a good predictor of its abundance in a plant community (Austin et al. 1985; Groves et al. 2003). Such a relationship could have useful consequences for resource management, as many natural plant communities are showing changes in composition that appear to be driven by shifts in relative competitive ability attributable to eutrophication (e.g. Austin \& Austin 1980; Ehrenfeld 1983; Newman et al. 1996, 1998; Woo \& Zedler 2002; Keddy \& Fraser 2002). These changes may cause rapid losses of biodiversity in natural plant communities (Moore et al. 1989; Keddy 2005). Although large sets of species have now been screened for relative competitive ability (e.g. Gaudet \& Keddy 1988; Keddy et al. 2002) an explicit test of their predictive power has not yet been made. Our study was designed to test whether a set of these previously-measured estimates of relative competitive ability could predict the composition of experimental wetland communities subjected to four levels of nutrients and two levels of disturbance.

Since the study used a $4 \times 2$ mixture of stress and disturbance (sensu Grime 1979), it had potential to simultaneously contribute evidence to the long-running debate regarding the relative role of competition along a productivity gradient. Some evidence suggests that the intensity of competition increases with increased fertility or productivity (Grime 1973; Austin et al. 1985; Campbell et al. 1991; Twolan-Strutt \& Keddy 1996), although others argue that competition remains constant from low to high productivity (Newman 1973; 
Tilman 1988). If competition intensity does vary with productivity, the predictability of community composition might depend on productivity as well (Austin et al. 1985; Gaudet \& Keddy 1995; Rajaniemi et al. 2003). Our two objectives were to test both propositions: 1 . Can an independent measure of relative competitive ability predict plant abundance in experimental plant communities? 2. Does fertility or disturbance influence the strength of the relationship? We used 11 plant species, varying greatly in size and relative competitive ability, to test these propositions. These species are frequent in shoreline wetlands of the Ottawa River and Georgian Bay area of Canada (Keddy 1981; Brunton \& Di Labio 1989; Moore et al. 1989). Although they differ in size and in habitat, they also occur in mixed communities (Wilson \& Keddy 1986a, b; Gaudet \& Keddy 1988, 1995).

Many indices of plant competition have been proposed and tested (see Keddy 2001; Weigelt \& Jolliffe 2003 for partial reviews). One way to determine relative competitive ability of plants is to compare the response of an individual plant grown in monoculture to the same species grown in mixture; another is to use a subset of species as 'phytometers' to screen large sets of species for relative competitive effect simultaneously. The first approach, the prediction of species performance in multi-species mixtures from that in monocultures, has proven successful (Austin et al. 1982, 1985; Campbell \& Grime 1992; Garnier et al. 1997; Navas et al. 2002; Groves et al. 2003). Austin et al. (1985) showed further that the relationship varies with nutrient level and that the slope of the regression lines increases with nutrient level and the associated increase in total biomass. We test the generality of the Austin et al. (1985) conclusions, but use the second approach to assessing relative competitive ability. In our study, the measure of relative competitive ability had been established for a set of 44 wetland plants that Gaudet \& Keddy (1988) had grown with one common neighbour species, or phytometer, Lythrum salicaria. Relative competitive ability of each species was assessed as the ability of the target species to reduce the phytometer biomass, and was expressed as follows:

$C P_{i}=\left(P_{1}-P_{2 i}\right) / P_{1} \times 100$

where $C P_{i}$ is the relative competitive ability of the $i$ th species; $P_{1}$ is the biomass of the phytometer grown alone (control) and $P_{2 i}$ is the mass of the phytometer when grown with the $i$ th species (Gaudet \& Keddy 1988). A few simple traits such as above-ground biomass and plant height could explain much of the variation in relative competitive ability $\left(r^{2}=0.74\right)$. In a first field test Gaudet \& Keddy (1995) found that this measure of relative competitive ability successfully predicted the distribution of 40 species in natural wetlands. We now will test whether the same measure of relative competitive ability can predict the composition of experimentally created plant mixtures.

We created gradients of soil fertility and disturbance. Since acquisition of mineral resources, particularly nitrogen $(\mathrm{N})$ and phosphorus $(\mathrm{P})$, are fundamental requirements for all plants (e.g. Weaver \& Clements 1929; Morowitz 1968; Marschner 1995), we created habitats varying in $\mathrm{N}$ - and P-availability: no added nutrients, full nutrients except $\mathrm{N}$, full nutrients except $\mathrm{P}$, and full nutrients. This treatment was applied to vary community productivity. We then superimposed clipping as a disturbance since the removal of aboveground biomass would remove acquired resources from the plant, and more importantly, reduce competition for light. Non-equilibrium models of community organization assume that disturbance can cause a reduction in the intensity of competitive interactions (Grime 1973; Huston 1979; Suding \& Goldberg 2001) and clipping has been applied as a disturbance treatment in other experimental communities (Fraser \& Grime 1999; Fynn et al. 2005). The influence of disturbance on competitive interactions, and the interacting effects of soil fertility, are not well understood (Goldberg \& Barton 1992), but recent studies are helping to clarify the interactive effects of disturbance and fertility on competitive ability (Suding \& Goldberg 2001; Osem et al. 2004; Fynn et al. 2005).

Our primary objective was to test whether relative competitive ability of individual species could predict the abundance of those same species in mixtures, and whether the answer was influenced by fertility or clipping. Simultaneously, however, the design allowed us to investigate whether the intensity of competition (inferred from the slope and $R^{2}$ of the relationship between relative competitive ability and species abundance in mixture; see Austin et al. 1985; Groves et al. 2003) changed with environment. The experiment was designed to provide data for a mixture of 11 species over two years where both the availability of belowground resources and rates of canopy removal were rigorously controlled. 


\section{Methods}

Ramets from 11 wetland species were collected from the field over two weeks in late June and early July of 1997 (Table 1) and placed in cold storage until planting on July 7. They represented a subset of the 44 species that were measured by Gaudet \& Keddy (1988), with special care taken to include a wide range of relative competitive ability values (from 1 to $96 \%$ ). All of these are native to wetlands, particularly shorelines, in eastern North America and the Great Lakes basin, with the exception of the exotic invasive Lythrum salicaria, and naturally occur together in associated plant communities (Day et al. 1988; Moore \& Keddy 1989; Brunton \& Di Labio 1989).

We established 5660 -L containers $(40 \mathrm{~cm}$ wide $\times 60$ $\mathrm{cm}$ long $\times 25 \mathrm{~cm}$ deep ) with $20 \mathrm{~cm}$ of autoclaved builder's sand in the Carleton University greenhouse. One ramet of ca. $3 \mathrm{~g}( \pm 0.02 \mathrm{~g})$ wet weight from each of the 11 species was randomly planted in a pre-assigned grid, each spot being separated by $10 \mathrm{~cm}$ from other spots and from the sides of the containers. By standardizing initial plant size, we reduced the potential for introducing an uncontrolled size bias in the competitive response of our 11 species (Gerry \& Wilson 1995). We chose to use ramets instead of seeds because plants growing from ramets tend to have faster initial growth than seedlings, thus hastening the potential for competitive interactions. The water level was maintained at $-5 \mathrm{~cm}$ relative to the soil surface by regular watering and holes drilled in the containers at the appropriate level. No artificial lights or temperature control was applied.

The experimental design included a $4 \times 2$ factorial combination of fertilization with seven replicates - with the following amounts of $\mathrm{N}$ and $\mathrm{P}$ per week:

$\begin{array}{lcc}\text { 'none' = no nutrients } & 0 \mathrm{mg} \mathrm{N} & 0 \mathrm{mg} \mathrm{P} \text {; } \\ \text { 'no-N' = full nutrients except } \mathrm{N} & 0 & 31 \\ \text { 'no-P' = full nutrients except P } & 56 & 0 \\ \text { 'full' = full nutrients } & 56 & 31 \\ \text { clipping: no clipping, clipping to } 10 \mathrm{~cm} \text { above soil }\end{array}$

We used Rorison's nutrient solution for the full fertilization treatment and a modified Rorison's for the no-N and no-P treatments (Hendry \& Grime 1993); 1 L of nutrient solution, or water for the 'none' treatment, was applied to each container one week after planting, and continued on a weekly basis until the end of October.

The clipping treatment began the last week of August and continued weekly until the end of October. In November of the first growing season, the holes in the containers were plugged, and the plants were flooded under $5 \mathrm{~cm}$ of water until April of the following growing season. The plugs were then removed to allow the plants to resume summer growth and the fertility treat-
Table 1. Wetland species $(n=11)$ used in the experiment. Competitive ability values (relative to Lythrum salicaria) are from Gaudet \& Keddy (1988).

\begin{tabular}{lcc}
\hline Species & Abbreviation & $\begin{array}{c}\text { Competitive } \\
\text { ability (\%) }\end{array}$ \\
\hline Lythrum salicaria & Lsal & 96 \\
Phalaris arundinacea & Paru & 89 \\
Acorus calamus & Acal & 67 \\
Hypericum ellipticum & Hell & 62 \\
Carex crinita & Ccri & 58 \\
Lysimachia terrestris & Lter & 44 \\
Onoclea sensibilis & Osen & 40 \\
Dulichium arundinaceum & Daru & 37 \\
Eleocharis smallii & Esma & 29 \\
Juncus pelocarpus & Jpel & 23 \\
Ranunculus reptans & Rrep & 1 \\
& & \\
\hline
\end{tabular}

ment resumed weekly until November. In addition, the clipping was re-initiated and continued on a weekly basis until November. At this time (the end of two complete growing seasons) we harvested the plants, sorted them to species and separated above-ground and below-ground parts. The plants were then ovendried at $60{ }^{\circ} \mathrm{C}$ for ca. $48 \mathrm{~h}$ and weighed. Due to handling errors, two of the containers were lost: one receiving no nutrients and no cutting and one receiving no nutrients and cutting.

Linear regression was applied to test the power of relative competitive ability to predict mean dry plant biomass per species (natural log-transformed) in mixture across the eight experimental treatment conditions. We also calculated linear regressions for aboveand below-ground parts but do not present the data because the results are similar to the total biomass results and thus do not add to the interpretation. In addition, linear regressions were calculated for relative competitive ability and species dry biomass for each container community $(n=54)$, and two properties were derived for each nutrient and clipping treatment: mean slope, mean $R^{2}$. Two two-way, fixed-effect ANOVAs were used to assess differences in these two properties among treatments.

A three-way, fixed-effect ANOVA was used to determine the response of biomass to species, fertility and clipping. A two-way ANOVA assessed the response of the root:shoot ratio to fertility and cutting. Data were natural log-transformed to satisfy assumptions of homoscedasticity and normality of residuals. All analyses were performed using Systat version 8.0 (Anon. 1998). 

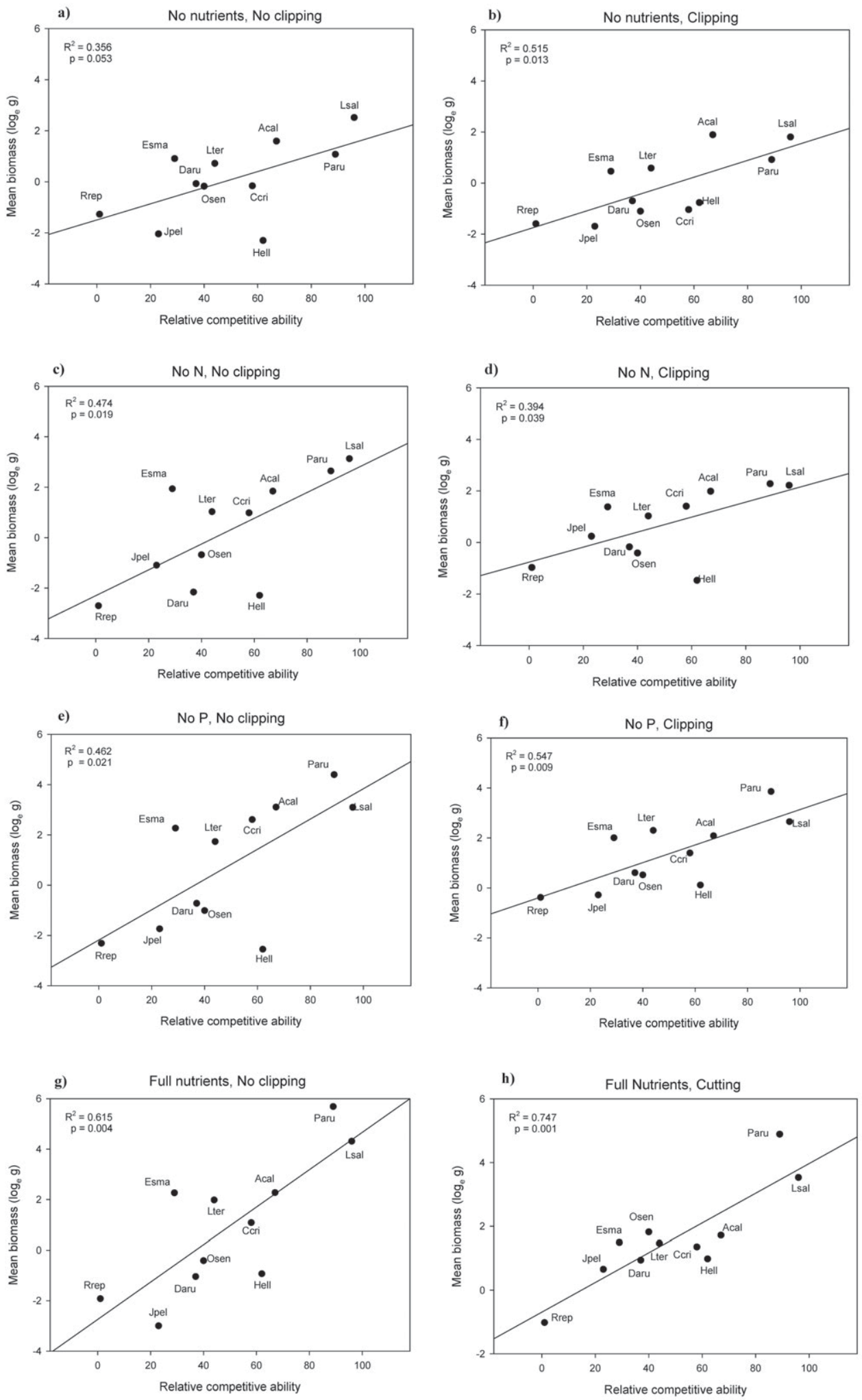

Fig. 1. The relationship between mean total dry biomass and competitive ability for 11 wetland plant species (Table 1) grown in mixture under eight different nutrient and clipping scenarios ( $n=6$ or 7 for each treatment, see Methods). 


\section{Results}

All relationships between mean total dry biomass of each species in mixture and relative competitive ability for the eight nutrient by clipping treatments are significant, and all the slopes are positive (Fig. 1). The only marginally significant relationship ( $p=0.053$ ) occurred in the no nutrients/no clipping treatment. The $R^{2}$ values ranged from 0.356 (Fig. 1a - no nutrients/no clipping) to 0.747 (Fig. $1 \mathrm{~h}$ - full nutrients/clipping). Species with the highest relative competitive ability tended to have the greatest mean biomass in mixture. Lythrum salicaria, the species with the highest relative competitive ability (Table 1), had the greatest mean biomass in treatments that did not contain nitrogen and were not clipped (Fig. 1a, c). In all of the other treatments but one, Phalaris arundinacea had the greatest mean biomass. The one exception occurred with no nutrients and clipping (Fig. 1b), where Acorus calamus had the greatest mean biomass. Generally, the species with the lowest mean biomass across treatments were Ranunculus reptans, Juncus pelocarpus and Hypericum ellipticum.

$R^{2}$-values differed with nutrient treatment, but not with clipping or the interaction between nutrients and clipping (Table 2). The greatest mean $R^{2}$ occurred with the full nutrient treatment (Fig. 2a). The treatments with no nutrients had the lowest $R^{2}$, while the no-P and no-N treatments had intermediate values. Mean slope differed among nutrient and clipping treatments, but there was no nutrient by clipping interaction (Table 2). The slope was greatest for full nutrients, followed by no $\mathrm{P}$, no $\mathrm{N}$ and no nutrients (Fig. 2b). Clipping decreased the slope of the regression line for all nutrient treatments.

The three-way ANOVA showed significant effects of species, nutrients and clipping on mean $\log _{\mathrm{e}}$ biomass of the 11 wetland plants (Table 3). Interactions between species and nutrients, and species and clipping were also significant. In general nutrient addition increased and clipping reduced biomass. Total mean biomass (all plants combined, data not shown) was greatest in treatments receiving full nutrients and no clipping, and least in treatments with no nutrients and clipping. The treatments without $\mathrm{N}$ had a lower biomass than those without $\mathrm{P}$.

Table 2. Results of two two-way ANOVAs examining the effects of nutrients (NUTR) and clipping (CLIP) on $\mathrm{R}^{2}$ and slope for the relationship between species total dry biomass $\left(\log _{\mathrm{e}} g\right)$ and competitive ability.

\begin{tabular}{lrrrcr}
\hline & \multicolumn{2}{c}{$R^{2}$} & \multicolumn{2}{c}{ Slope } \\
Source & $d f$ & $F$-ratio & \multicolumn{1}{c}{$p$} & $F$-ratio & $p$ \\
\hline NUTR & 3 & 6.144 & $<0.001$ & 58.22 & $<0.001$ \\
CLIP & 1 & 0.792 & 0.378 & 23.66 & $<0.001$ \\
NUTR $\times$ CLIP & 3 & 0.203 & 0.894 & 1.48 & 0.232 \\
ERROR & 46 & & & & \\
\hline
\end{tabular}
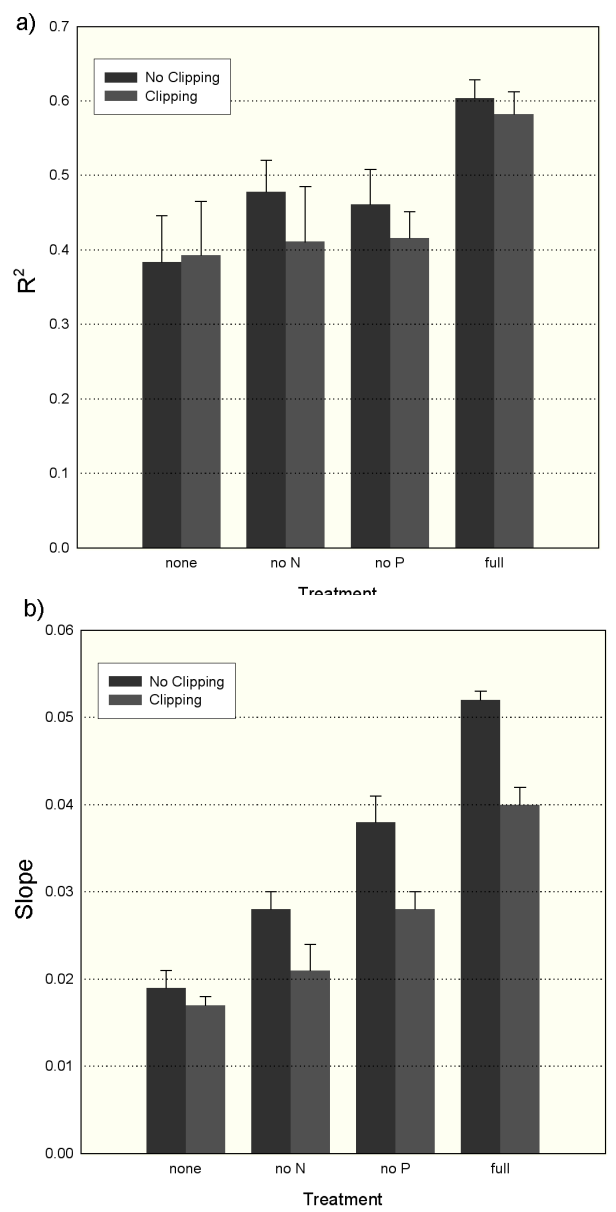

Fig. 2. Intensity of competition for a mixture of 11 wetland plant species (Table 1) grown under differing environmental conditions (see Methods) as reflected by (a) mean $R^{2}( \pm 1 \mathrm{SE})$ and (b) mean slope $( \pm 1 \mathrm{SE})$ for the relationship between total dry biomass and competitive ability ( $n=6$ or 7 , see Methods).

The two-way ANOVA on root:shoot ratios showed that both nutrients and clipping had significant effects (Table 4). As expected, clipping increased the root:shoot ratio, while the addition of $\mathrm{N}$ reduced the root:shoot ratio. There was no significant interaction between nutrients and clipping.

Table 3. Results of a three-way ANOVA examining the effects of the 11 wetland species (SPECIES), the four nutrient treatments (NUTR), and the two clipping treatments (CLIP) on total plant dry biomass $\left(\log _{\mathrm{e}} g\right)$.

\begin{tabular}{lrrrr} 
Source & Sum-of-squares & $d f$ & $F$-ratio & $p$ \\
SPECIES & 2704.264 & 10 & 87.76 & $<0.001$ \\
NUTR & 141.484 & 3 & 15.30 & $<0.001$ \\
CLIP & 15.625 & 1 & 5.07 & 0.025 \\
SPECIES $\times$ NUTR & 208.702 & 30 & 2.26 & $<0.001$ \\
SPECIES $\times$ CLIP & 108.603 & 10 & 3.52 & $<0.001$ \\
NUTR $\times$ CLIP & 17.592 & 3 & 1.91 & 0.126 \\
SPECIES $\times$ NUTR $\times$ CLIP & 109.087 & 30 & 1.18 & 0.237 \\
ERROR & 1559.289 & 506 & & \\
\hline
\end{tabular}




\section{Discussion}

The first objective was to test the power of Gaudet \& Keddy's (1988) estimates of relative competitive ability to predict species performance in mixture. Species reported by them as having a higher relative competitive ability, such as Phalaris arundinacea and Lythrum salicaria, produced significantly greater biomass, while species with relatively low competitive abilities (e.g. Ranunculus reptans and Juncus pelocarpus) had lower biomass in our experimental mixtures. These patterns emerged across eight different sets of environmental conditions produced by nutrient additions and clipping (Fig. 1). These results are also in accordance with Austin et al. (1985), who showed that relative biomass in monoculture predicts performance in multispecies mixture.

We emphasize that the species and individuals in our experiment were independently collected from natural habitats more than a decade after the study by Gaudet \& Keddy (1988), our experiment was in a different location (Carleton University as opposed to the University of Ottawa), and our plants grew in a greenhouse instead of outside. In spite of these differences, the data from one set of experiments could predict patterns in another, accounting for up to $74.7 \%$ of the variation in biomass in our experimental communities.

Two tools have been proposed to assess the relationship between competition intensity and the environment: the slope of the relationship, and the proportion of variance accounted for by the relationship (Austin et al. 1985; Weldon \& Slauson 1986; Weldon et al. 1988; Jolliffe 1997; Keddy 2001). Although we used these tools, we emphasize that our experiment was not designed to specifically test interspecific competitive interactions - only controlled monoculture and mixture experiments can do this. Experiments at this scale often do not include monocultures for comparison (e.g. Grime 1987; Weiher \& Keddy 1995; Fraser \& Keddy 1997). Hence, it is not possible using our design to separate the relative impacts of different relative growth rates, different tolerances to low nutrients, different tolerances to clipping, and different competitive abilities (among

Table 4. Results of a two-way ANOVA examining the effects of the four nutrient treatments (NUTR) and the two clipping treatments (CLIP) on the ratio between below- and aboveground dry biomass $\left(\log _{\mathrm{e}} g\right)$.

\begin{tabular}{lrrrr}
\hline Source & Sum-of-Squares & $d f$ & $F$-ratio & $p$ \\
\hline NUTR & 77.484 & 3 & 10.55 & $<0.001$ \\
CLIP & 4.882 & 1 & 8.80 & 0.005 \\
NUTR $\times$ CLIP & 1.196 & 3 & 0.72 & 0.546 \\
ERROR & 25.514 & 46 & & \\
\hline
\end{tabular}

others) that may have contributed to the observed composition of the experimental communities.

Using the slopes of the relationships, which are often assumed to be a measure of competition intensity (e.g. Austin et al. 1985), our data are consistent with the proposition that competitive intensity increases with fertility (Austin et al. 1985; Campbell \& Grime 1992; Twolen-Strutt \& Keddy 1996; Callaway et al. 2002), and that clipping reduced the intensity of competition (Huston 1979; Osem et al. 2004). The highest mean slope occurred in the nutrient treatments that contained full nutrients and were not clipped. The lowest slopes occurred when nitrogen was absent, and these slopes were further reduced by clipping. Correspondingly, the nutrient treatments containing nitrogen (Fig. 1 e-h) also had greater productivity measured as total plant biomass. Austin et al. (1985) also showed that the steepness of a regression line between a competitive ability index and relative plant biomass grown in mixture increases with nutrient level. Fig. 1 suggests that plants with higher relative competitive abilities were more competitively dominant when they were not clipped (e.g. Huston 1979; Osem et al. 2004). Clipping lowered the biomass of these strong competitors, and resulted in an increase in biomass of poor competitors. One mechanism that might account for these patterns would be competition for light, which was reduced when clipping prevented a canopy from closing.

The variation accounted for by the regression line, $R^{2}$, suggests that competitive intensity increases with fertility, and that clipping had little further effect. $R^{2}$ was highest (0.747) in the treatment with full nutrients and disturbance (leaves clipped every week). The treatment that was stressed (no nutrients supplied for two years) and not clipped had the lowest $R^{2}(0.356)$ and a marginally significant relationship ( $p=0.053$ ) between biomass and relative competitive ability. Although the artificial clipping was non-selective, unlike herbivory (e.g. Fraser \& Grime 1999), it did do the most damage to the tallest plants with the highest growth form, such as Phalaris arundinacea. Clipping may also have intensified below-ground competition by forcing clipped plants to forage for nutrients to construct new shoots (Tilman 1988; Berendse \& Elberse 1990; Suding \& Goldberg 2001; MacDougall \& Turkington 2004). The significance of this relationship may also have been reduced by greater variability in response - these plants would be most susceptible to minor differences in factors such as recovery from transplantation, initial growth rates, position effects within the container, minor topographic differences within containers, position effects or differences in water supply among containers, etc. Irrespective of the choice of slope or $R^{2}$, however, competition intensity increased when nutrients were increased. 
We emphasize that the main objective of this experiment was to test whether relative competitive ability can predict the composition of communities, and how much this might vary with conditions in those communities. Our results show in general that predictive models based upon systematic measures of plant traits are a reasonable and practical goal (see also Shipley 1994; Grime 2001; Keddy 2001; Freckleton \& Watkinson 2001). The power of prediction seems to vary with the environmental conditions. The mechanisms that underlie these patterns remain unclear, and illustrate why there are still debates over mechanisms of competition. The search for general quantitative relationships in nature is fundamental to the advancement of theoretical and applied ecology (Rigler 1982; Keddy 1987, 2005; Peters 1992; Shipley 2000). Plant traits, such as relative competitive ability, may provide an important tool for improving our predictive capacity.

Acknowledgements. We thank Kristina Makkay for help with the maintenance and harvest of the containers. Ed Bruggink, head horticulturalist of Carleton University greenhouse was very helpful throughout our experiment. Statistical and theoretical discussions with R. Mitchell were much appreciated, and comments by C. Carlyle, C. Keddy and L. Feinstein on earlier drafts were helpful. Comments from Wim Braakhekke and Mike Austin have improved this manuscript.

\section{References}

Anon. 1998. SYSTAT ${ }^{\text {TM }}$ 8.0 Statistics. SPSS Inc., Chicago, IL, US.

Austin, M.P. 1982. Use of a relative physiological performance value in the prediction of performance in multispecies mixtures from monoculture performance. J. Ecol.70: 559570.

Austin, M.P.\& Austin, B.O. 1980. Behaviour of experimental plant communities along a nutrient gradient. J. Ecol. 68: 891-918

Austin, M.P., Groves, R.H., Fresno, L. \& Kaye, P.E. 1985. Relative growth of six thistles along a nutrient gradient with multispecies competition. J. Ecol.73: 667-684.

Berendse, F. \& Elberse, W. 1990. Competition and nutrient availability in heathland and grassland ecosystems. In: Grace, J.B. \& Tilman, D. (eds.) Perspectives on plant competition, pp. 93-116. Academic Press, San Diego, CA, US.

Brunton, D.F. \& Di Labio, B.M. 1989. Diversity and ecological characteristics of emergent beach flora along the Ottawa River in the Ottawa-Hull region, Quebec and Ontario. Naturaliste Canadien 116: 179-191.

Callaway, R.M., Brooker R.W., Choler, P., Kikvidze, Z., Lortie, C.J., Michale, R., Paolini, L., Pugnaire, F.L., Newingham, B., Aschehoug, E.T., Armas, C., Kikodze, D. \& Cook, B.J. 2002. Positive interactions among alpine plants increase with stress. Nature 417: 844-848.

Campbell, B.D. \& Grime, J.P. 1992. An experimental test of plant strategy theory. Ecology 73: 15-29.

Campbell, B.D., Grime, J.P., Mackey, J.M.L. \& Jalili, A. 1991. The quest for a mechanistic understanding of resource competition in plant communities: the role of experiments. Funct. Ecol. 5: 241-253.

Day, R., Keddy, P.A., McNeill, J. \& Carleton, T. 1988. Fertility and disturbance gradients: a summary model for riverine marsh vegetation. Ecology 69: 1044-1054.

Ehrenfeld, J.G. 1983. The effects of changes in land-use on swamps of the New Jersey pine barrens. Biol. Conserv. 25: 353-375.

Fraser,L.H. \& Grime, J.P. 1999. Interacting effects of herbivory and fertility on a synthesized plant community. J. Ecol. 87: 514-525.

Fraser, L.H. \& Keddy, P. 1997. The role of experimental microcosms in ecological research. Trends Ecol.Evol. 12: 478-481.

Freckleton, R.P. \& Watkinson, A.R. 2001. Predicting competition coefficients for plant mixtures: reciprocity, transitivity and correlations with life-history traits. Ecol. Lett. 4: 348-357.

Fynn, R.W.S., Morris, C.D. \& Kirkman, K.P. 2005. Plant strategies and trait trade-offs influence trends in competitive ability along gradients of soil fertility and disturbance. J. Ecol. 93: 384-395.

Garnier, E., Navas, M.-L., Austin, M.P., Lilley, J.M. \& Gifford, R.M. 1997. A problem for biodiversity-productivity studies: how to compare the productivity of multispecific plant mixtures to that of monocultures? Acta Oecol. 18: 657670.

Gaudet, C. \& Keddy, P.A. 1988. A comparative approach to predicting competitive ability from plant traits. Nature 334: 242-243.

Gaudet, C. \& Keddy, P.A. 1995. Competitive performance and species distribution in shoreline plant communities: a comparative approach. Ecology 76: 280-291.

Gerry, A.K. \& Wilson, S.D. 1995. The influence of initial size on the competitive responses of 6 plant-species. Ecology 76: 272-279.

Gleason, H.A. \& Cronquist, A. 1991. Manual of vascular plants of Northeastern United States and adjacent Canada, 2nd. ed. New York Botanical Garden, New York, NY, US.

Goldberg, D.E. \& Barton, A.M. 1992. Patterns and consequences of interspecific competition in natural communities: a review of field experiments with plants. Am. Nat. 139: 771-801.

Grace, J.B. \& Pugesek, B.H. 1997. A structural equation model of plant species richness and its application to a coastal wetland. Am. Nat. 149: 436-460.

Grime, J.P. 1973. Competitive exclusion in herbaceous vegetation. Nature 242: 344-347.

Grime, J.P. 1979. Plant strategies and vegetation processes. John Wiley, Chichester, UK.

Grime, J.P. 2001. Plant strategies, vegetation processes, and ecosystem properties. 2nd. ed. John Wiley, Chichester, $\mathrm{UK}$.

Grime, J.P., Mackey, J.M.L., Hillier, S.H. \& Read, D.J. 1987. 
Floristic diversity in a model system using experimental microcosms. Nature 328: 420-422.

Groves, R.H., Austin, M.P. \& Kaye, P.E. 2003. Competition between Australian and introduced grasses along a nutrient gradient. Austral Ecol. 28:491-498.

Hendry, G.A.F. \& Grime, J.P. 1993. Methods in comparative plant ecology: a laboratory manual. Chapman \& Hall, London, UK.

Huston, M. 1979. A general hypothesis of species diversity. Am. Nat. 113: 81-101.

Jolliffe, P.A. 1997. Are mixed populations of plant species more productive than pure stands? Oikos 80: 595-602.

Keddy, P.A. 1981. Vegetation with Atlantic coastal plain affinities in Axe Lake, near Georgian Bay, Ontario. Can. Field-Nat. 95: 241-248.

Keddy, P.A. 1987. Beyond reductionism and scholasticism in plant community ecology. Vegetatio 69: 209-211.

Keddy, P.A. 2001. Competition. 2nd. ed. Kluwer, Dordrecht, NL.

Keddy, P.A. 2005. Putting the plants back into plant ecology: six pragmatic models for understanding and conserving plant diversity. Ann. Bot. 95: 1-13.

Keddy,P.A. \& Fraser,L.H. 2002. The management of wetlands for biological diversity: four principles. In: Ambasht, R.S. $\&$ Ambasht, N.K. (eds.) Modern trends in applied aquatic ecology, pp. 21-42. Kluwer, New York, NY, US.

Keddy, P., Nielsen, K., Weiher, E. \& Lawson, R. 2002. Relative competitive performance of 63 species of terrestrial herbaceous plants. J. Veg. Sci. 13: 5-16.

MacDougall, A. \& Turkington, R. 2004. Relative importance of suppression-based and tolerance-based competition in an invaded oak savanna. J. Ecol. 92: 422-434.

Marschner, H. 1995. Mineral nutrition of higher plants. 2nd. ed. Academic Press, London, UK.

Moore, D.R.J. \& Keddy, P.A. 1989. The relationship between species richness and standing crop in wetlands: the importance of scale. Vegetatio 79: 99-106.

Moore, D.R.J., Keddy, P.A., Gaudet, C.L. \& Wisheu, I.C. 1989. Conservation of wetlands: do infertile wetlands deserve a higher priority? Biol. Conserv. 47: 203-217.

Morowitz, H.J. 1968. Energy flow in biology: biological organization as a problem in thermal physics. Academic Press, New York, NY, US.

Navas, M.-L., Garnier, E., Austin, M.P., Viaud, A. \& Gifford, R.M. 2002. Seeking a sound index of competitive intensity: application to the study of biomass production under elevated $\mathrm{CO}_{2}$ along a nitrogen gradient. Aust. Ecol. 27: 463-473.

Newman, E.I. 1973. Competition and diversity in herbaceous vegetation. Nature 244: 310.

Newman, S., Grace, J.B. \& Koebel, J.W. 1996. Effects of nutrients and hydroperiod on Typha, Cladium and Eleocharis: implications for Everglades restoration. Ecol. Appl. 6: 774-783.

Newman, S., Schuette, J., Grace, J.B., Rutchey, K., Fontaine, T., Reddy, K.R. \& Pietrucha, M. 1998. Factors influencing cattail abundance in the northern Everglades. Aquatic Bot. 60: 265-280.
Osem, Y., Perevolotsky, A. \& Kigel, J. 2004. Site productivity and plant size explain the response of annual species to grazing exclusion in a Mediterranean semi-arid rangeland. J. Ecol. 92: 297-309.

Peters, R.H. 1992. A Critique for ecology. Cambridge University Press, Cambridge, UK.

Rajaniemi, T.K. 2002. Why does fertilization reduce plant species diversity? Testing three competition-based hypotheses. J. Ecol. 90: 316-324.

Rajaniemi, T.K., Allison, V.J. \& Goldberg, D.E. 2003. Root competition can cause a decline in diversity with increased productivity. J. Ecol. 91: 407-416.

Rigler, F.H. 1982. Recognition of the possible: an advantage of empiricism in ecology. Can.J.Fish.Aqu.Sci.39: 13231331.

Shipley, B. 2000. Cause and correlation in biology: a user's guide to path analysis, structural equations and causal inference. Cambridge University Press, Cambridge, UK.

Shipley, B. \& Keddy, P.A. 1994. Evaluating the evidence for competitive hierarchies in plant communities. Oikos 69: 340-345.

Suding, K.N. \& Goldberg, D.E. 2001. Do disturbances alter competitive hierarchies? Mechanisms of change following gap creation. Ecology 82: 2133-2149.

Tilman, D. 1988. Plant strategies and the dynamics and structure of plant communities. Princeton University Press, Princeton, NJ, US.

Twolan-Strutt, L. \& Keddy, P.A. 1996. Above- and belowground competition intensity in two contrasting wetland plant communities. Ecology 77: 259-270.

Weaver, J.E. \& Clements, F.E. 1929. Plant ecology. McGrawHill, New York, NY, US.

Weigelt, A.\& Jolliffe, P. 2003. Indices of plant competition. J. Ecol. 91: 707-720.

Weiher, E. \& Keddy, P.A. 1995. The assembly of experimental wetland plant communities. Oikos 73: 323-335.

Weldon, C.W.\& Slauson, W.L. 1986. The intensity of competition versus its importance: an overlooked distinction and some implications. Q. Rev. Biol. 61: 23-44.

Weldon, C.W., Slauson, W.L. \& Ward, R.T. 1988. Competition and abiotic stress among trees and shrubs in northwest Colorado. Ecology 69: 1566-1577.

Wilson, S.D. \& Keddy, P.A. 1986a. Species competitive ability and position along a natural stress/disturbance gradient. Ecology 67: 1236-1242.

Wilson, S.D \& Keddy, P.A. 1986b. Measuring diffuse competition along an environmental gradient: results from a shoreline plant community. Am. Nat. 127: 862-869.

Woo, I. \& Zedler, J.B. 2002. Can nutrients alone shift a sedge meadow towards dominance by the invasive Typha $\mathrm{x}$ glauca? Wetlands 22: 509-521.

Received 27 June 2005; Accepted 22 August 2005. Co-ordinating Editor: M. Austin. 